\title{
Fifty Shades of Gay: Social and Technological Change, Urban Deconcentration and Niche Enterprise.
}

\author{
Alan Collins, University of Portsmouth \\ Stephen Drinkwater, Roehampton University London
}

\begin{abstract}
The development of urban gay villages in England has previously been explored via the conceptual toolkit of the New Economic Geography. While arguably retaining explanatory legitimacy in historical perspective, looking forward, its validity is contended to be terminally undermined by changes in broader macro-social trends. The intention of this work is to address a relative lack of attention devoted to broader macro-level processes contributing to the decline or significant re-configuration of urban gay areas. A revised developmental model is presented and considered as part of a transition stage towards a post gay era.
\end{abstract}

\section{Introduction}

Earlier work exploring the evolution of urban gay districts sought to explain their genesis and growth via amenity and disposable income-based (hedonic) reasoning, contingent on some previous "historical accidents" in lesbian and gay male settlement patterns (Black et al, 2002). Later work by Collins (2004a) has drawn on key concepts in the New Economic Geography as propounded by Krugman (1997) among others to posit a somewhat more comprehensive, critical population size based-explanation to account for both the emergence and the stages of development of various urban gay villages or districts. Working at this general conceptual level is clearly distinct from the current vogue for detailed ground-level case studies and satisfies different purposes. That said, the latter can clearly inform the former. More specifically, we address the question as to whether one can model changes in urban gay areas without formally examining them directly, relying solely on broader macro-level social and technological trends to explain their decline or re-configuration. This study is premised on the view that such a macro-level focus is both legitimate and feasible and contributes to a relative lacuna in work devoted to the larger scale processes shaping the decline and re-configuration of urban gay areas. The work is informed by multiple strands of evidence which although not necessarily providing conclusive evidence on the pattern and strength of causality of these broader social and technological trends, do combine to highlight the likely mix of important contributory factors leading to the decline and re-configuration of such urban gay spaces.

A reading of the developmental model in Collins (2004a) might suggest that such 'decline' eventually takes the form of integration and assimilation (as observed in an earlier study by Kirkey and Forsyth, 2001). Others have suggested actual displacement of lesbian and gay space (see, for example, Ruting, 2008; Doan and Higgins, 2011) has taken place. Accordingly, the scope for geographical transferability of the model in recent years has been reasonably criticised and questioned (Anderrson, 2011; Lewis, 2013). That said, universal direct applicability without at least some modest cross-cultural modifications was never explicitly claimed to be readily feasible. Nevertheless, taken together as a body of work, in historical retrospect, these studies can be argued to have at least offered a range of plausible, though not necessarily mutually exclusive possibilities to analyse the phenomenon of urban gay districts and their developmental trajectories. They may also potentially help inform egalitarian, socially liberal and enlightened public and planning policy seeking to nurture 
and sustain these urban amenities and resources for their citizens (Doan, 2011; Doan and Higgins, 2011; Smart and Klein 2013; Kusek, 2015). However, the rapid pace of various distinct and often overlapping social, urban and technological changes that have taken place in the opening two decades of the twenty-first century already warrants a wholesale reappraisal of the status and likely growth paths of these districts and seriously questions the ongoing validity of the extant academic literature as a guide to future development.

In this study, the key sources of such change for urban gay villages and districts in the specific context of English towns and cities are set out and that these are acknowledged to be largely the purview of gay men rather than the full spectrum of the gay, lesbian, bisexual, transgender population. By retaining this wholly English geographical focus an attempt is made to control for some cross-cultural factors influencing the phenomenon under scrutiny. That said, Whittemore and Smart (2015) have also found evidence for a similar dispersal/deconcentration and potential decline narrative through tracking gay adverts for property rentals and for-sale properties in a US city. In this paper, however, focussing primarily on England, the outcome and future ramifications for the viability of such districts are explored from an explicitly economistic perspective in the light of various strands of secondary evidence. These include, inter alia, some spatial and regional disaggregation of "British Social Attitudes" (BSA) survey data; lesbian and gay news sources; numbers and composition of social and partner search apps readily available to download and some statistical trends in public house closures and social network and relationship partner search methods. Additionally, some online presence count data is presented to inform the discussion on social and partner search in a sample of English villages, small and medium-sized towns and large towns and cities.

The key findings that may be distilled from this study are threefold. (i) Looking forward the developmental model of urban gay villages in England as set out in Collins (2004a) no longer provides an adequate guide to future development trajectories.(ii) The future possibility raised in that study (p. 1802) of a declining phase in urban gay districts and a long run equilibrium consisting of a relatively small group of large urban gay villages in cities and a larger number of much smaller gay districts, warrants wholesale revision. More specifically, the 'declining' phase in urban gay districts in England has seemingly already taken hold at a more rapid than then anticipated pace. Scrutiny of their presence, decline and relatively recent absence in many towns in England suggests they are, in the main, disappearing. (iii) Liberal social change, the growth of many and varied openly gay and lesbian orientated recreational and social clubs and societies, web platform social networks and the commonplace ubiquity of friend and partner search apps on smartphones have reduced the demand for, and thus rendered seemingly redundant, most smaller gay districts (and their cornerstone - gay pubs).

In essence, almost any home, café and pub can potentially feature, to a very limited extent, some of the functions of physical gay venues. Indeed various studies surveyed herein suggest that websites such as Gaydar, apps such as Grindr, Scruff and Growlr and app versions of some websites such as Gaydar, serve as important social and meeting spaces in gay men's lives. They can be chosen to displace (when deployed) the regular need for specific physical gay meeting venues. Arguably, they are reducing the motivation and frequency of long distance leisure commuting or migration to larger towns and cities due to their population size and thus better partner search matching on specific (niche) characteristics of desire. Niche focussed enterprise has also been one of the greatest beneficiaries of the shift to online commercial platforms, reducing overhead costs to producers/suppliers and reducing both out-of-pocket and time search costs for niche consumers. A lower bound estimate of web or app enabled partner search among gay men for meeting new sexual contacts is $40-50 \%$ (Liau et al, 2006; Grov et al, 2013). Inevitably even these seemingly high figures 
do not take into account the numbers of very infrequent and highly covert users, some already ensconced in gay male or otherwise heterosexual relationships.

The paper is organised in the following manner. In section 2 more recent theoretical arguments and broader commentary on the forces changing the size and character of urban gay villages and districts in the twenty-first century are outlined and briefly considered. The following section draws on secondary and primary evidence to set out some 'stylized facts' that better inform the general future trajectory of urban gay districts/villages in England. In section 4 the stylized facts are used to revise and extend, from the 'Integration' phase, the developmental model of urban gay villages set out in Collins (2004a). This is undertaken to better take account of the English experience of urban deconcentration and physical decline, but to also recognise the concomitant experience of social and market diffusion of lesbians and gay males through many other physical and virtual spaces (see, for example, Kirkey and Forsyth, 2001). It is contended that this is characteristic of the movement to a so-called "post-gay era". These often feature a legacy of attachment via psychically important physical commemorative markers for visitors and lesbian and gay households residing, or at least in social and leisure commuting distance of, the fewer core urban gay districts/villages that are left in larger city locations. A summary and some concluding remarks are offered in the final section.

\section{The Development of Urban Gay Spaces in the Twenty-First Century: Brief Retrospect and Prospect}

Since 2000 there have been a number of case studies drawing out differences in the character and development of urban gay spaces around the world. In the context of mature industrial economies there has been considerable diversity, including observations of recreational specialisation (with mixed success) in world cities with multiple gay districts (see, for example, Andersson, 2011). Others have observed active "re-making" of some gay districts (such as South Beach, Florida). Kanai and Kenttamaa-Squires (2015) find this re-making has resulted in a "...LGBT-friendly mixed neighborhood increasingly shaped by the pro-equality, but primarily pro-tourism and redevelopment, politics of the City" [p.13] and shaped by the forces of "homonormative entrepreneurialism." There have also been calls for greater attention to explore the features and dimensions of gay spaces and lives in the multitude of ordinary towns as distinct from large cities and metropolises (Brown, 2008) or what otherwise might be termed the tyranny of 'metronormativity' (Podmore, 2013).

An emerging and increasingly recurrent theme relates to overlapping narratives of physical decline of some gay spaces. For Collins (2004a) such decline in the English context was envisaged to be part of a development trajectory of assimilation of the area into the fashionable mainstream. The beginnings of this process commences with the development of an urban area already featuring urban decline which then progresses through a number of broad stages of economic enterprise. These stages feature the presence of activities characterised by sexual and legal liminality; the expansion of gay male social and recreational opportunities; widening of the service-sector business base to meet the demands of a growing gay/lesbian market demand and then ultimately assimilation as these businesses are patronised by the fashionable mainstream. The growing gay/lesbian market demand was hypothesised in Collins (2004a) to be an artefact of cumulative self-reinforcing population growth since a larger gay/lesbian population and its attendant commercial support services is for some individuals provides a source of increased amenity value drawing, in turn drawing in further gay/lesbian in-movers. Yet since much of this increased amenity is also of appeal to the fashionable (predominantly heterosexual) population mainstream, then the seeds of a move to assimilation are also potentially sown. 
Some work attributes or characterises this assimilation as deliberate encroachment and appropriation of distinctive LGBT space (Ruting, 2008, Kanai and Kenttamaa-Squires, 2015). For some others it is in large part due to greater and willing adoption of (ii) shared sexuality social spaces and also more isolated or transient social spaces in other city locations and (iii) an increasing focus on the experience of more overtly residential (and often suburban) gay neighbourhoods (gaybourhoods) as opposed to a reliance or focus on more traditional gay village services typically comprising a mixed land use clustering featuring several lesbian/gay entertainment venues and retail outlets (see, for example, Reynolds, 2009, Browne and Bakshi, 2011, Lewis, 2011 and Nash, 2013).

Speculating on how gay identities have been constituted and how they may change in the future is not a particularly recent practice (see, for example, Sinfield,, 1998) but the study of Nash (2013) seems to raise the notion that these spatial changes may be conceived by some very specific segments of the gay male population (specifically a younger more privileged subset) as part of an inexorable movement to an increasingly post-gay era (or indeed post-modern homosexual self-identification or "post-mo"). Nevertheless, she still contends that "....physical places, no matter how contested still remain a touchstone." In a similar vein, Ghaziani (2014a,b) highlights (particularly in the context of Chicago's Boystown) the continuing perceived importance of gay districts for housing "anchor institutions" despite considerable and ongoing residential out-migration (or deconcentration). Further, he shows that in these districts physical markers of commemoration (such as the rainbow pillars and metal plated LGBT historical figure biographies) can provide a clear indication of an urban sexual culture with a durable legacy valued by many individuals (particularly among his survey respondents). This durability broadly aligns with the concept of vicarious citizenship set out by Greene (2014) which may “...help explain why gay neighborhoods remain relevant among certain LGBT populations who, for a variety of reasons, select into neighborhoods outside established gay areas." [p.1].

For Ghaziani (2014a) the term post-gay can be “... a mode of self-identification, a way to describe the features of a specific space, a characteristic of an entire neighborhood and a way to think about the zeitgeist of a historical moment" [p.374]. Thus people who identify as post gay are argued to be less territorially defensive of gay spaces and more open to share these and any other social spaces in their city where clearly distinguishing sexualities is simply not that important or felt to be necessary. That said, post-gay does not necessarily fully translate into 'post discrimination' (Ghaziani, 2011) and this seems inevitable given that trends in social attitudes may tread an often slow crossgenerational path, Thus residual intolerance is a likely durable feature in some specific segments of a society's population and which may be revealed in routine housing market processes (Christafore and Leguizamon, 2012; Christafore et al, 2013). Such intolerance has been typically associated with strong religious conservatism (see NatCen 2013).

Few geographical studies beyond Ruting (2008), which focus on the development trajectories of urban gay spaces have, hitherto, moved on to explicitly consider the role of social networks and various partner search websites and apps as potentially significant contributors to the processes of decline, reduced in-migration and active deconcentration in gay districts/villages. Yet the literature at the nexus of academic social science and on-the ground public sexual health practice shows that this channel of interaction is now substantial. Accordingly, public health workers have had to shift resources and markedly change their modus operandi to make contact with the vast majority of men who have sex with men (MSM) (see, for example, Burrell et al, 2012; Landovitz et al, 2013; Grosskopf et al, 2014; Grov et al, 2014). MSM indicates a population beyond men who currently identify themselves as gay or bisexual and includes those who are ostensibly in heterosexual relationships but engage at least intermittently in homosexual activity. Social apps may be hidden or masked on hand held mobile devices and website histories cleared systematically such that this aspect 
of their lives can be sustained covertly by technological means. Likewise, young MSM may organize and explore their sexuality more readily at lower cost - i.e. without necessarily requiring any recourse to extensive travel or migration to cities with large urban gay villages (McKie et al, 2015). They view their findings as "...helping to mitigate negative conceptualizations of Internet use among gay men." In terms of the theoretical sketch set out in Collins (2004b) this would equate to both a reduced divergence between, and a shift outwards of, resource constraints for rural and urban residents in the sexual 'market place'.

\section{Drivers of Change: Social Change and Socio-Technological Developments}

There are several strands of relevant evidence that that have contributed to changes in the geographical extent, development and pattern of usage of urban gay districts and villages in England. As with other segments of the population, key life transitions prompted by ageing, having children etc. will typically impact on residential location decisions. Yet there are also broader macro-social and macroeconomic trends, allied to widely diffused adoption of technological innovations that can potentially influence such decisions. More micro-level individual behavioural changes in social networking and partner search may thus build on such macro-trends. The empirical evidence presented herein is not identified as or claimed to be completely definitive but does highlight trends warranting further scrutiny. These are considered in turn.

\section{Changing Social Attitudes}

Empirically exploring matters pertaining to sexuality generally and same sex relationships specifically can be problematic for various reasons pertaining to sampling and survey design, but in the context of England and Wales there was even antipathy from the UK Government during the 1980s compounding difficulties (for a discussion see, Cameron et al, 2009). Nevertheless, in particular years since 1983, based on responses to their question in the British Social Attitudes (BSA) survey asking the degree to which homosexual relations are "wrong", NatCen (2013), show that across Great Britain, attitudes have become more tolerant over time. They surmise that this indicates that the British population have reflected positively on legislative changes relating to civil partnerships and same sex marriage and also to public figures being open about their homosexuality. However, they note that this trend has been at times "bumpy" such as around the early 1980s where there was debate, divisiveness and hysteria around the HIV/AIDS epidemic and the introduction of Section 28 in the 1988 Local Government Act intended to support more 'traditional family values'.

More recently, BSA data suggests a slight increase in intolerance, with the percentage of responding that homosexual relations were always wrong rising from $20 \%$ in 2010 to $22 \%$ in 2012. This was the first increase in this measure recorded since 1990, although the percentage responding that homosexual relations were not wrong at all continued to rise up to 2012. The increase in less tolerant attitudes could be due to (i) a general shift in social attitudes (as perhaps also indicated by changing political views) or (ii) more specific factors such as increased immigration, or (iii) some combination of (i) and (ii). Point (ii) is relevant to this study because the BSA survey indicates recent migrants to the UK tend to have less tolerant attitudes to homosexuality, in part due to higher levels of religious conservatism among migrants. NatCen (2013) highlight the strong linkage between religious belief and tolerance. Though declared tolerance (i.e. low disapproval of homosexuality) is growing for all irrespective of religion, it is greatest for non-religious individuals and lowest (i.e. highest disapproval) for those with non-Christian religious beliefs.

There are, however, important nuances in the spatial differences in tolerance that have potential bearing on the impetus to move to areas perceived to be more 'gay-friendly'. Looking first at the 
mean attitudes to homosexual relations in the regions, analysis of the BSA microdata undertaken in this study (see Table 1) indicates that attitudes have indeed become more tolerant in all regions over time, with large changes, for example, in Wales, Yorkshire and Humberside and the North East of England, all of which initially had the least tolerant attitudes in the BSA data series. ${ }^{i}$ The smallest changes are in London, the region with initially the most tolerant attitudes. However, for London the immigration story may be playing a more significant role in shaping the regional metric of tolerance. This will be explored further below.

Delving deeper into this BSA data in order to highlight the extremes of the attitudinal spectrum to homosexual relations we can see from Table 1 that although the data show a consistently declining trend in the percentage of respondents reporting "homosexuality is always wrong", this figure was actually highest in London in 2010-12, the region where it had been second lowest in 1985-7. In contrast, there have been large falls in the percentage in this category in other regions. The most startling decline can be seen in Yorkshire and Humberside, where just 13\% considered homosexual relations to be always wrong in 2010-12, compared to $62 \%$ in 1985-7. Focusing on the percentage of the population reporting that homosexual relations are not wrong at all, we find that all regions show a consistently increasing trend in the percentage holding the most tolerant views. Consistent with the previous discussion, the most recent data (2010-12) indicate that the pace of change has been far greater in Yorkshire and Humberside and the North-East of England than in London, South-East England and the West Midlands. London in particular has witnessed a relative decline in the percentage of the population holding the most tolerant views since it ranked second from bottom, after the West Midlands, amongst the regions according to the proportion of respondents considering homosexual relations to be not wrong at all. London was the highest ranked region in this category in 1985-7. Accordingly, this may serve to lessen, for some individuals, London's allure as the principal beacon of homosexual tolerance and thus weakened the magnetic draw of London, and to some extent Birmingham, as a source of lesbian and gay in-migration.

Turning to urban/rural differences, the BSA survey asks respondents to describe the place they live and this response has also been used to examine 'attitudes to homosexuality'. Again, there are important nuances in the spatial differences revealed. From Table 2, it is clear that mean attitudes to homosexual relations were most intolerant in rural areas, small towns and city suburbs in the second half of the 1990s but that the spatial pattern of attitudes has changed since then. In particular, the "big city" and suburban environs of London have seemingly become relatively less tolerant to homosexuality over recent years in comparison to other parts of Britain, with the sharpest increase in tolerance reported in areas outside London. Focusing on the least tolerant segment of respondents, who think homosexual relations are "always wrong"; there is a consistent pattern of decline over the period, apart from the two London areas. For example, the percentage in this category fell by less than 8 points in the "Big City" parts of London between 1995-2000 and 2006-2012, compared to a fall of more than 18 points in the rural parts of England and Wales. Moreover, there was an increase in the percentage of respondents in suburban parts of London who thought that homosexual relations were always wrong between 2001-5 and 2006-12. There has also been an increase in the percentage with the most tolerant attitudes in urban and rural areas outside London across the three time periods. Over $40 \%$ of respondents in each of these areas considered homosexual relations not to be wrong at all in the most recent time period. This compared to a figure of less than $35 \%$ in the London suburbs, which also represented a decline on the figure recorded in the preceding period. Whereas in the "Big City" parts of London, there was no change in the percentage of respondents who thought that homosexual relations were not wrong at all across the last two periods. 
Therefore, although attitudes towards homosexual relations have become far more tolerant right across the UK over the past couple of decades, there is evidence that there has been a recent reversal of this trend in London. As mentioned previously, a possible explanation for this may be political change and/or that parts of London now have heavy concentrations of immigrants, who are more likely to display conservative attitudes, especially if they have strong (non-Christian) religious beliefs. Unfortunately, the BSA survey does not collect any information on country of birth, however, questions on ethnic group and religion are asked. Therefore, the combination of information on broad ethnicity and religion may provide some indication of the impact of demographic, as well as wider social, change. It is also well known that university graduates have more liberal attitudes and that London has long been a magnet for young graduates (Fielding, 1992). Table 3 therefore presents information from the BSA surveys on the changing characteristics of respondents in the urban-rural areas within Britain over the same three periods examined in Table 2.

Table 3 reveals that the percentage of ethnic minorities in London has risen far more rapidly than across the rest of Britain, increasing by more than 12 percentage points in both parts of the capital between 1995-2000 and 2006-12, compared to less than 3 percentage points across Britain as a whole. Mean attitudes towards homosexual relations by ethnic minorities were more or less unchanged over the three periods (and were actually lowest/most tolerant in the first period) but fell quite steadily for Whites. A similar pattern is apparent if information on other religions is examined. ii

\section{Rise of the Machines: Online and App-Based Partner Search}

There is a substantial body of literature emerging on the role of new media on gay urban spaces (e.g. Mowlabocus (2010), Usher and Morrison (2010) as well as a vast array of research on LGBT life online (particularly queer youth) and the creation of community among other things (see, for example, the survey in Hubbard et al 2015). Cassidy (2013), for example, shows that new media (e.g. Facebook) and online life is interwoven with offline life in bars and other cruising spots in quite complicated ways, and in ways that are reworking how material spaces are experienced.

In terms of the narrower objectives bound up with our principally economistic perspective, digital world engagement clearly present scope and opportunities for lowering supply-side (business) costs and lowering consumer search costs compared to' physical world' transactions. In $201280 \%$ of households in Great Britain had Internet access and this figure rises to over $90 \%$ in households with children (Office for National Statistics, 2012) with the trend moving upwards. In terms of smartphone usage, $72 \%$ of people between the ages of 16 and 64 own a smartphone with percentage ownership much higher among younger age bands (Styles, 2013). We may thus also infer that app users have a lower mean age. With population change, the usage trend is thus also upward. Accordingly, many independent and chain retail outlets have observed increasingly greater volumes of purchases from their own or competitor online store operations. The lower overhead costs of principally webplatformed business and the low search costs of online ordering has as Anderson (2007) observed facilitated the emergence of a large number of niche enterprises catering to niche markets alongside the much smaller number of larger volume producers/suppliers catering to the 'mass market'. This phenomenon he describes as the emergence of the 'long tail', implying a Pareto-type distribution in production and supply of goods and services. Commercial partner search seems to readily align with this long tail thinking, though in this case, supply has shifted almost entirely to web or app platformed operation and there are sites and apps catering to broadly defined categories or search pools of partners (e.g. gay men) as well as many more targeted to specific partner types (e.g. hairy men, older men, fetishwear aficionados). 
All these sites have typically free basic membership and many offer 'premium' or enhanced functionality on a free basis for a limited time period. As such they offer users extensive and potentially immediate general or niche (specific characteristics-laden) partner search at low cost across the entire country. Specifically in terms of apps, scrutiny of Google Play Store on $21^{\text {st }}$ February 2015 showed that for lesbian and gay dating there are 89 such apps available to download (if one also includes general dating apps (such as Tinder) which have options for searching for lesbian or gay partners). Of these 42 are specifically aimed at gay or bisexual men. There were 5 apps specifically aimed at women who identify as bisexual or lesbian and with much lower reported downloads. For Batiste (2014) use of apps such as Grindr presents a "re-mapping of social space" which regularly reminds users of clear numerical evidence indicating that the public sphere is less heteronormative than might be assumed. Further, he argues that given these apps facilitates face to face contact through their geo-locational features; they nurture social networking and friendship bonds among gay men beyond territorially explicit gay spaces. For some gay and bisexual men, however, locationally aware mobile technology means that the virtual online world becomes intertwined with their offline world (Blackwell et al, 2014) such that it may complicate interactions by co-situating diverse groups of acquaintances, friends and family members. For some 'out' gay or bisexual men this poses no problems. For others a need has emerged to manage potentially multiple online and offline identities (Gudelunas, 2012) which may before these online worlds emerged have been more clearly geographically distinct. Accordingly, there here have now emerged apps (such as u2nite) which enable sight of users in a local area but with the app 'blurring' the user's actual location. It is also worth noting that there will also be many gay men in long term monogamous relationships who do not use these apps or websites at all and thus usage cannot be used to gross up to provide population estimates of the gay male population in a particular location

To provide a snapshot of their usage among gay/bisexual men in a selection of English cities outside London and also some medium sized towns and villages across the regions a simultaneous count of the online presence in these locations was undertaken by three individuals within a one hour period (1800-1900hrs) on a Saturday (21/02/2015). The search process was previously piloted and rehearsed. The stability of the count was checked for a sub-sample of the chosen locations (of different sizes) near the start of the hour and towards the end. The count used two apps (Hornet and Growlr) and one website (Gaydar - which also has an app platform) which all permit online geographical search functionality across England by place name. Both Hornet and Gaydar are general gay dating and partner search channels, with Hornet claimed to be second only to Grindr in terms of number of downloads from Google Play Store. The Growlr app is targeted specifically at one niche market - members and admirers of the gay 'bear' sub-culture. For an explanation and discussion of the nature, features and extent of this phenomenon see Hennen (2005) and Manley et al (2007). The count survey did not include the market leading app for gay/bisexual men - Grindr, principally because it does not offer the required cross country search functionality. Even though gay men with mobile technology typically use a variety of such apps and thus have more than one profile, exclusion of the market leader must mean our data (Table 4) provides only an indicative lower bound estimate of online activity during this hour. Yet this would also be the case even if Grindr could be used since this app, alongside others, does permit users to apply 'filtering' options to exclude profiles with particular characteristics (e.g. excluding those under or over a certain age). Profiles on Gaydar may also be selected to be 'hidden' from search lists.

Table 4 sets out these lower bound estimates of the immediate online search pool at a variety of different sized locations across England using the place name search function. For three of the city locations, namely, Birmingham, Brighton and Manchester, which are major gay population centres, these cities are defined search 'regions' within which people search in Gaydar. This means that the 
number of profiles specifically using these city names in their profile is actually far lower than the number in the surrounding area who also considers themselves part of the search pool of these places. Furthermore, in the free version of Growlr used, the maximum number of profiles in any given place name search that may be viewed is 124 . So where this value is reported in the Growlr results, this is only a lower bound figure of online presence.

The scope to determine in Gaydar the number of profiles within a given location also provides some indication of the numerical extent of the search pool using that channel and thus also the online ratio of visible profiles. For the medium sized towns/cities in the count sample this value is fairly consistent ranging from $16 \%$ to $23 \%$ of users online in those locations. This suggests approximately a fifth of Gaydar users were online within these medium sized towns/cities during the count and it may be (mindful of market overlaps due to multiple profiles) this figure can translate across to other similar apps, including those catering to a more niche market.

What is perhaps unsurprising is the small numbers choosing to be revealed online at that time in the villages and small towns surveyed (see, for example Wells next the Sea, Dymchurch and Mevagissey). However, for several of the medium sized towns/cities the immediate search pool, across the country, at that time seems fairly substantial in both the mainstream channels - Gaydar and Hornet and also the niche market app, Growlr. See, for example, the online numbers in Burnley, Chichester, Durham, Scunthorpe and Shrewsbury. Thus in these locations, individuals with average tastes but also many with some more specific tastes will likely have a reasonably sized 'backstop' search pool immediately available to initiate potential social or sexual contact. Thus the use of this technology can potentially impact on the trading vitality of local gay pubs (in terms of their role as a social and sexual partner meeting venue), particularly among more income constrained younger age cohorts.

\section{Pubs}

Historically, public houses (pubs) in the UK have occupied a key role in supporting and building lesbian and gay communities and gay districts/villages (Collins 2004a) but now even the basic question as to whether gay pubs are needed any longer has entered the realm of popular discourse (Belonsky, 2013; Hotson, 2014). A lower or negligible frequency of visits to support partner search and social networking has been linked to more liberal social attitudes and the use of websites and apps for partner search. Yet irrespective of these phenomena there has been a serial decline in customer demand for pubs and thus a steady decline in the number of pubs remaining in business (Preece 2008). The total number of pubs in the UK has steadily fallen each year from 67,800 in 1983 to 48,006 in 2013, even though beer sales have recently started to grow again, albeit not just from pub sales (BBPA, 2015). Clearly pubs catering for LGBT customers cannot have been immune to the social and economic forces contributing to this broader sectoral decline (see, for example, Gloucester Citizen, 2015; Walters, 2015). These include changing tastes among the young for socialising in other types of venues, outlets and for other activities (Pratten, 2003; Andrews and Turner, 2012; Roberts and Townshend, 2013).

It is difficult to obtain sources of accurate and consistent data on the numbers of gay pubs, clubs and other liquor-licenced premises over time in Britain. Nevertheless we do provide some information of this pattern over time from the listings within the UK publication, Gay Times, from the British Library for five-year intervals covering the period 1985 to 2005. The data for each March issue are presented in Table 5. The March issue was chosen to control for any post-festive period effects (e.g. special pop-up Christmas/New Year venues). Between 2005 and 2010 the listing information went completely online only. 
In overview, Table 5 shows that the number of licenced venues grew from 1985-2000 and the growth was quite rapid in areas outside London. The growth appeared to have continued in some medium/large cities up to 2005 but this was at a slower rate, whereas there was a noticeable decline in the number of venues in London (and Manchester) as well as some falls in other cities. That said, there has been considerable flux or churn in the venues appearing in the London listings and in terms of their location within London. ${ }^{\text {iii }}$

Stylized facts

Distilling the statistical and other evidence examined it is possible to develop some stylized facts to help inform the subsequent reconsideration and extension of developmental models of urban gay districts/villages in England as typified by Collins (2004a). These are set out below.

(i) There is a trend indicating increasingly tolerant attitudes to homosexuality over time and space, spatially extending beyond a few core metropolitan regions typified by liberal social attitudes and durably permeating into regions formerly typified by more conservative social attitudes.

(ii) There is a spatial trend featuring increasingly tolerant attitudes to homosexuality moving across the urban to rural spectrum, which has been accentuated in some larger urban areas by population changes associated with immigration.

iii) The diffusion of Internet access and mobile-based apps contributes to the erosion of the demand for commercially sustained physical gay spaces, venues and enterprises.

(iv) The diffusion of Internet access and mobile-based apps reduces the search and transaction costs for gay male 'partner' search across both broad and more niche 'bundles' of desired characteristics.

\section{Integration, Decline and Diffusion of Urban Gay Spaces}

Many large towns and cities in England have had sizable gay villages or districts with a relatively wide supporting services sector base. That they have evolved in some locations often from only one institution (typically a pub) and often in off-central locations has been explored in Collins (2004a). That evolutionary trajectory is characterized and depicted as Stages 1 to 3 in the developmental model contained therein. Taking a prospective gaze it is possible to take account of the stylized facts established in the previous section to re-fashion the 'Integration' phase of that model and formally extend the model. A gay critical mass population was deemed the key requirement for the evolution and sustainability of the network of gay villages and districts that came to be established in England in the Twentieth century. Looking forward in the light of our stylized facts, this critical mass seems now destined to rapidly dissipate and diminish over time (in terms of both numbers of gay households and commercial entities). As a consequence physical decline is prompted in the network of gay villages and districts in England, alongside decline in the geographical extent, volume and variety of gay village and district services in any given location. The model extension is set out in Table 6 .

The model suggests that the retrenchment to a smaller commercial core of such gay villages can be simply conceived of as the outcome of revenue considerations. Those remaining seem likely to be those that have more diversified and hence resilient revenue streams, including significant spending from LGBT tourists (and their friends) and also a substantial social and leisure commuting segment of the LGBT population (and their friends). This residual core is thus more likely to host the remaining physical 'anchor institutions' and largely serve to support the 'vicarious community' and 'vicarious citizenship' needs of a much more geographically extensive LGBT hinterland than was previously the case in the late Twentieth century. Increasingly, the centre of gravity of the gay socialscape is 
envisaged to change. It is suggested that the trend is for this to become highly spatially diffuse and become largely a feature of suburban areas and small and medium-sized towns across England. It is contended that mainstay channel of LGBT social and sexual community will, in effect, primarily reside in the online world but physically occupy mainstream social spaces whenever required.

Rural settlements, over a longer time period, are also argued to become subject to these same socio-technological changes as suggested by the stylized facts. Displacing much long distance leisure/social commuting to urban gay villages, rural LGBT residents are thus anticipated to more routinely align to suburban or small/medium sized town LGBT online social worlds and relationship search pools.

As noted above in the discussion of evidence from the BSA survey, the spatial picture with regards to attitudes towards homosexual relations has changed significantly over the past two decades. The largest reductions in negative attitudes towards homosexuality have been observed outside of London, especially in rural parts of Britain. Allied to this convergence in attitudes, a trend towards more intolerant views towards homosexual relations appear to have emerged in London in recent years, thereby reversing a pattern of ever more liberal attitudes towards homosexuality. Demographic change, particularly with respect to immigration, now seems to be a playing an important role here and may be making London a less attractive location for gay men and lesbians, especially given the other influences identified in the paper.

Ultimately the model characterizes physical and socio-technological change that triggers and traces a transition path from integration of gay villages and districts into the fashionable mainstream through to a post gay era where the clear momentum of gay social and sexual activity lies for most individuals well beyond city locations. That said in some of these cities that retain LGBT anchor institutions, there will still remain strong connectivity denoted by the bonds and ties of vicarious citizenship.

\section{Summary and Concluding Remarks}

Developmental models and case studies of urban gay villages and districts since 2000 have been reviewed and reassessed in this paper in the light of substantial socio-technological developments and changing social attitudes. Decline and/or significant re-configuration has been widely identified. We find that here has even been some significant contraction in numbers of entertainment and partner meeting venues in the few larger city-based urban gay villages excluding London. In the case of London there has been significant churn and re-location. For the larger city-based urban gay villages this pattern of decline and reconfiguration has taken place despite them benefitting from a larger, more diversified (and thus arguably resilient) revenue base by virtue of social and leisure commuting from a wider regional hinterland and their status as domestic tourist amenities and attractions.

Significant socio-technological changes are argued to have been an important contributing factor, irrespective or regardless, of any perceptions or observations suggesting the successful outcome of revanchist appropriation of valorised lesbian and gay spaces for capital accumulation. That said, with contraction and decline, even if only due to structural changes in demand, retail and entertainment venue properties in gay villages are inevitably sold for similar or changed use for non-lesbian and gay male targeted custom. Furthermore, routine residential property sales by lesbian and gay households to heterosexual households must take place. Inevitably this can contribute to a change of character for some gay districts and villages.

Additionally, in the specific context of England, where a cornerstone feature of gay villages and districts - the gay pub - was considered instrumental in the evolution of gay spaces as they moved to 
a critical gay population size - the situation has dramatically changed. There has been broad sectoral decline in the wider UK pub sector. However, coupled with lower pub usage by smartphone using gay men and lesbians (particularly by the more 'digital native' younger age cohorts), this has prompted many gay pub closures and thus discernible contraction in the level of provision.

Analysis of the BSA microdata undertaken for this study has revealed increasing tolerance to homosexual relations across the country and across the urban-rural spectrum. Allied to the technological developments afforded by the Internet and mobile geo-locational social and partner search apps, the lifestyle pressure for gay men and lesbians to migrate to big cities, or engage in high frequency long-distance social and leisure commuting, has been eroded. Hence, while the critical gay population mass argument may have had some considerable explanatory legitimacy in an historical perspective, looking forward, this argument seems to have frayed and been undermined. Online social networks and partner search apps make available both broad and niche desire characteristics more readily available, even in outer suburbs and smaller towns and cities across England. This has been demonstrated empirically through the results of a snapshot count survey of gay male 'online presence' across the English regions, in settlements of various sizes.

More recent data from the BSA survey suggests that London has also seen some growth in segments of its population holding the least tolerant attitudes to homosexuality. For some lesbian and gay households it can be a discernible tension that may serve to dampen London's specific appeal as an attractive long-term residential option. Possible explanations for this finding have been explored and may be linked to high levels of immigration into London, especially in connection to those individuals holding more conservative religious attitudes. This is also likely to be compounded by high overall house prices in the capital (and a higher cost of living more generally).

Various strands of supporting empirical evidence have been distilled into a set of stylized facts. These have, in turn, been used to inform, revise and extend the developmental model of urban gay villages and districts in England as set out in Collins (2004a). In so doing, the model moves further into line with recent work suggesting that metronormative analyses of gay spaces should give way to a greater analytical focus on the challenges, lives and experiences of lesbian and gay households in suburban areas and small/medium-sized town settings. The changes identified in this paper also suggest that the spatial distribution of the homosexual population, and supporting, industries, is likely to display further fluidity in the future.

\section{Acknowledgements}

The authors are grateful for the helpful comments and insights of all the reviewers which have contributed to significantly improving the paper. The usual caveat applies.

\section{References}

ANDERSON, C (2007) The Long Tail: How Endless Choice is Creating Unlimited Demand. London: Random House.

ANDERSSON, J. (2011) Vauxhall's post-industrial Pleasure Gardens: 'death wish' and hedonism in 21st-century London, Urban Studies, 48, 85-100.

ANDREWS, D. and TURNER, S. (2012) Is the pub still the hub?, International Journal of Contemporary Hospitality Management, 24, pp.542 - 552.

BATISTE, D.P. (2014) '0 Feet Away': The Queer Cartography of French Gay Men's Geo-social Media Use, Anthropological Journal of European Cultures, 22, pp. 111-132. 
BELONSKY (2013) The End of the Gay Bar, Ctd. Out.com, July $29^{\text {th }}$. Available from: http://www.out.com/entertainment/popnography/2013/07/29/end-gay-bar-ctd [date accessed: 28/01/15]

BLACKWELL, C., BIRNHOLTZ, J. and ABBOTT, C. (2014) Seeing and being seen: Co-situation and impression formation using Grindr, a location-aware gay dating app, New Media \& Society, 16, pp. 1-20.

BRITISH BEER AND PUB ASSOCIATION (BBPA) (2015) Statistics, Available from http://www.beerandpub.com/statistics [data accessed February 1st 2015]

BROWN, G. (2008) Urban (Homo)Sexualities: Ordinary Cities and Ordinary Sexualities, Geography Compass, 2, pp. 1215-1231.

BROWNE, K. and BAKSHI, 1. (2011) We are here to party? Lesbian, gay, bisexual and trans leisurescapes beyond commercial gay scenes, Leisure Studies, 30, pp.179-196.

BURRELL, E.R., PINES, H.A., ROBBIE, E., COLEMAN, L., MURPHY, R.D., HESS, K.L., ANTON, P. and GORBACH, P.M. (2012) Use of the Location-Based Social Networking Application GRINDR as a Recruitment Tool in Rectal Microbicide Development Research, AIDS and Behavior, 16, pp. 1816-1820.

CAMERON, S., COLLINS, A., DRINKWATER, S., HICKSON, F., REID, D., ROBERTS, J., STEPHENS, M. and WEATHERBURN, P. (2009) Surveys and Data Sources on Gay Men's Lifestyles and Socio-Sexual Behavior: Some Key Concerns and Issues, Sexuality \& Culture, 13, pp.135-151.

CASSIDY, E. M. (2013). Gay men, social media and self-presentation: managing identities in Gaydar, Facebook and Beyond. Queensland University of Technology e-prints: http://eprints.qut.edu.au/61773/1/Elija_Cassidy_Thesis.pdf [date accessed 03/07/2015]

CHRISTAFORE, D., and LEGUIZAMON, S. (2012) The influence of gay and lesbian coupled households on house prices in conservative and liberal neighborhoods. Journal of Urban Economics 71, pp. 258-267.

CHRISTAFORE, D., LEGUIZAMON, J. S., and LEGUIZAMON, S. (2013). Are black neighborhoods less welcoming to homosexuals than white neighborhoods? Regional Science and Urban Economics, 43, pp. 579-589.

COLLINS, A. (2004a) Sexual dissidence, enterprise and assimilation: Bedfellows in urban regeneration, Urban Studies, 41, pp. 1789-1806.

COLLINS, A. (2004b) Sexuality and sexual services in the urban economy and socialscape: An overview, Urban Studies, 41, pp1631-1641.

DOAN, P.L. (2011) Queerying Planning: Challenging Heteronormative Assumptions and Reframing Planning Practice, Farnham, Surrey, UK: Ashgate Publishing.

DOAN, P.L. and HIGGINS, H. (2011) The demise of queer space? Resurgent gentrification and the assimilation of LGBT neighborhoods, Journal of Planning Education and Research, 31, 16-25.

FIELDING, A. J. (1992). Migration and social mobility: South East England as an escalator region. Regional Studies, 26, pp. 1-15. 
GREENE, T. (2014). Gay Neighborhoods and the Rights of the Vicarious Citizen. City \& Community, 13, pp. 99-118.

GROV, C., BRESLOW, A.S., NEWCOMB, M.E., ROSENBERGER, J.G. and BAUERMEISTER, J.A. (2014) Gay and Bisexual Men's Use of the Internet: Research from the 1990s through 2013, Journal of Sex Research, 51, pp.390-409.

GHAZIANI, A. (2011) Post-gay collective identity construction, Social Problems, 58. pp. 99-125.

GHAZIANI, A. (2014a) Measuring urban sexual cultures, Theory and Society, 43, pp.371-393.

GHAZIANI, A. (2014b) There Goes the Gayborhood? Princeton, NJ: Princeton University Press.

GLOUCESTER CITIZEN (2015) Gloucestershire LGBT community rally around campaign to save The Westgate (03/02/2015) Available at: http://m.gloucestercitizen.co.uk/Gloucestershire-LGBTcommunity-rally-campaign/story-25966847-detail/story.html [Accessed: 10/02/2015].

GROSSKOPF, N.A., LEVASSEUR, M.T. and GLASER, D.B. (2014) Use of the Internet and MobileBased “Apps" for Sex-Seeking Among Men Who Have Sex With Men in New York City, American Journal of Men's Health, 8, pp. 510-520.

GROV, C., AGYEMANG, L., VENTUNEAC, A. and BRESLOW, A.S. (2013) Navigating Condom Use and HIV Status Disclosure with partners Met Online: A qualitative Pilot Study with Gay and Bisexual Men from Craigslist.org. AIDS Education and Prevention 25, pp. $72-85$.

GUDELUNAS, D. (2012) There's an App for that: The Uses and Gratifications of Online Social Networks for Gay Men, Sexuality \& Culture, 16, pp.347-365.

HENNEN, P. (2005) Bear bodies, bear masculinity: recuperation, resistance, or retreat? Gender \& Society, 19 , pp. 25-43.

HOTSON, E. (2014) Do gay people still need gay bars? BBC News Magazine, April $1^{\text {st }}$. Available at: http://www.bbc.co.uk/news/magazine-26817128 [date accessed 2nd April 2014]

HUBBARD, P., GORMAN-MURRAY, A., \& NASH, C. J. (2015). Cities and Sexualities. In J. DeLamater and R. Plante (eds) Handbook of the Sociology of Sexualities (pp. 287-303). Berlin: Springer International Publishing.

KANAI, J.M. and KENTTAMAA-SQUIRES, K. (2015) Remaking South Beach: metropolitan gayborhood trajectories under homonormative entrepreneurialism, Urban Geography, forthcoming (DOI:10.1080/02723638.2014.970413).

KIRKEY, K., and FORSYTH, A. (2001) Men in the valley: Gay male life on the suburban-rural fringe. Journal of Rural Studies, 17(4), 421-441.

KRUGMAN, P. (1997) How the economy organizes itself in space: a survey of the new economic geography, in: W.B.ARTHUR, S. DURLAUF and D.LANE (Eds) The Economy as an Evolving Complex System II: Proceedings, pp. 223-237. Boulder, CO: Westview Press.

KUSEK, W.A. (2015) Shifting the spotlight: suggesting a pragmatic approach to studying the Polish LGBT community, Journal of Urbanism: International Research on Placemaking and Urban Sustainability, 8, pp. 82-96. 
LANDOVITZ, R.J., TSENG, C-H., WEISSMAN, M., HAYMER, M., MENDENHALL, B., ROGERS, B., VENIEGAS, R., GORBACH, P.M., REBACK, C.J. and SHOPTAW, S. (2013) Epidemiology, Sexual Risk Behavior, and HIV Prevention Practices of Men who Have Sex with Men Using GRINDR in Los Angeles, California, Journal of Urban Health, 90, pp. 729-739.

LEWIS, N.M. (2011) Ottawa's Le/The Village: Creating a gaybourhood amidst the 'death of the village' Geoforum, 49, pp. 233- 242.

LIAU, A., MILLET, G. and MARKS, G. (2006) Meta-analytic examination of online sex-seeking and sexual risk behavior among men who have sex with men. Sexually Transmitted Diseases 33, pp. 576584.

MANLEY, E., LEVITT, H. and MOSHER, C. (2007) Understanding the bear movement in gay male culture: redefining masculinity, Journal of Homosexuality, 53, pp. 89-112.

MCKIE, R.M., LACHOWSKY, N.J. and MILHAUSEN, R.R. (20 15) The Positive Impact of Technology on Young Gay Men's Dating and Sexual Relationships in Canada: Results from a Focus Group Study, Journal of LGBT Youth, 12, pp.19-38.

MOWLABOCUS, S. (2010). Gaydar Culture. Farnham: Ashgate.

NASH, C.J. (2013) The age of the "post-mo"? Toronto's gay village and a new generation. Geoforum, pp. 243-252.

NatCen Social Research (2013) British Social Attitudes 30 - Homosexuality, London: NatCen Available at: http://www.bsa-30.natcen.ac.uk/read-the-report/personalrelationships/homosexuality.aspx [date accessed 01/02/2015]

OFFICE FOR NATIONAL STATISTICS (2012) Internet Access - Households and Individuals, 2012, Statistical Bulletin, London: ONS. Available at:

http://www.ons.gov.uk/ons/dcp171778_275775.pdf [date accessed 22/02/2015]

PODMORE, J. (2013) Critical commentary: Sexualities landscapes beyond homonormativity, Geoforum, 49, pp.263-267.

PRATTEN, J.D. (2003) Responding to Demand: New Types of Public Houses in the UK, Journal of Food Products Marketing, 9, pp.39-52.

PREECE, D. (2008) Change and continuity in UK public house retailing, Service Industries Journal, 28, pp.1107-1124.

REYNOLDS, R. (2009) Endangered territory, endangered identity: Oxford Street and the dissipation of gay life, Journal of Australian Studies, 33, 79-92.

ROBERTS, M. and TOWNSHEND, T. (2013) Young adults and the decline of the urban English pub: issues for planning, Planning Theory \& Practice, 14, pp.455-469.

RUTING, B. (2008) Economic transformations of gay urban spaces: revisiting Collins' evolutionary gay district model, Australian Geographer 39, pp.259-269.

SINFIELD, A. (1998) Gay and After: Gender, Culture and Consumption, London: Serpent's Tail.

SMART, M.J. and KLEIN, N.J. (2013) Neighborhoods of affinity: social forces and travel in gay and lesbian neighborhoods, Journal of the American Planning Association, 79, pp.110-124. 
STYLES, K., (2013) 7 in 10 People in the UK Now Own a Smartphone, Mobile Marketing, (24 June) Available from http://mobilemarketingmagazine.com/7-10-people-uk-now-own-smartphone/ [date accessed 17/02/2015]

USHER, N., and MORRISON, E. (2010). The demise of the gay enclave, communication infrastructure theory, and the transformation of gay public space. In C. Pullen and M. Cooper (eds) LGBT Identity and Online New Media, (pp. 271-287) Los Angeles, CA: Sage.

WALTERS, B. (2015) Closing time for gay pubs - a new victim of London's soaring property prices, The Guardian [online] ( $4^{\text {th }}$ February) Available at: http://www.theguardian.com/society/2015/feb/04/closing-time-gay-pubs-lgbt-venues-property-prices [date accessed 5 February 2015]

WHITTEMORE, A. H. and SMART, M.J. (2015) Mapping gay and lesbian neighborhoods using home advertisements: Change and continuity in the Dallas-Fort Worth Metropolitan Statistical Area over three decades. Environment \& Planning A (forthcoming) [DOI: 10.1177/0308518X15605095] 
Table 1: Attitudes towards Homosexual Relations by Region

\begin{tabular}{|c|c|c|c|c|c|c|c|c|c|c|c|c|}
\hline & \multicolumn{3}{|c|}{ \% "Always Wrong" } & \multicolumn{3}{|c|}{ \% "Not Wrong At All" } & \multicolumn{3}{|c|}{ Mean Rating } & \multicolumn{3}{|c|}{ Number of Observations } \\
\hline & 1985-7 & 1998-2000 & 2010-12 & 1985-7 & 1998-2000 & $2010-12$ & 1985-7 & 1998-00 & 2010-12 & 1985-7 & 1998-00 & $2010-12$ \\
\hline Scotland & 59.5 & 39.6 & 17.2 & 9.8 & 32.4 & 47.8 & 4.1 & 3.2 & 2.5 & 312 & 505 & 202 \\
\hline Wales & 71.4 & 42.7 & 17.7 & 10.5 & 28.3 & 45.3 & 4.3 & 3.4 & 2.5 & 183 & 313 & 130 \\
\hline Yorkshire \& & & & & & & & & & & & & \\
\hline Humberside & 62.2 & 37.4 & 12.9 & 8.7 & 29.8 & 53.6 & 4.2 & 3.2 & 2.2 & 306 & 554 & 185 \\
\hline North East & 58.5 & 38.1 & 22.1 & 13.7 & 32.6 & 50.6 & 4.1 & 3.2 & 2.4 & 218 & 350 & 106 \\
\hline North West & 61.6 & 38.6 & 18.7 & 10.0 & 31.7 & 49.0 & 4.2 & 3.2 & 2.5 & 376 & 551 & 277 \\
\hline West Midlands & 63.5 & 41.5 & 23.9 & 10.7 & 25.8 & 39.7 & 4.2 & 3.4 & 2.7 & 318 & 447 & 194 \\
\hline East Midlands & 66.2 & 38.6 & 24.6 & 9.0 & 28.0 & 45.4 & 4.3 & 3.2 & 2.6 & 236 & 450 & 203 \\
\hline South West & 65.1 & 36.5 & 15.6 & 9.8 & 31.3 & 45.5 & 4.3 & 3.1 & 2.5 & 271 & 510 & 199 \\
\hline Eastern & 64.3 & 39.4 & 22.9 & 7.8 & 27.3 & 46.1 & 4.3 & 3.3 & 2.5 & 120 & 261 & 217 \\
\hline South East & 55.8 & 33.7 & 18.8 & 15.0 & 32.2 & 43.8 & 4.0 & 3.1 & 2.6 & 567 & 1,057 & 264 \\
\hline London & 56.0 & 34.0 & 27.7 & 18.1 & 32.9 & 42.0 & 3.8 & 3.1 & 2.7 & 334 & 555 & 207 \\
\hline Great Britain & 61.1 & 37.4 & 20.5 & 11.7 & 30.6 & 45.8 & 4.1 & 3.2 & 2.5 & 3,241 & 5,553 & 2,184 \\
\hline
\end{tabular}


Source: British Social Attitudes Survey

Notes:

1. There was a change in regional boundaries in the BSA in 2006. However, the regional definitions should largely be consistent over time.

2. The percentage of respondents in each category and mean ratings is weighted.

3. Respondents who did not provide an answer or did not know have been removed from the mean ratings.

4. The number of observations is based on all responses to the questions and is unweighted.

\section{Table 2: Attitudes Towards Homosexual Relations by Urban-Rural Area}

\begin{tabular}{|c|c|c|c|c|c|c|c|c|c|c|}
\hline & \multicolumn{3}{|c|}{ \% "Always Wrong" } & \multicolumn{3}{|c|}{ \% "Not Wrong At All" } & \multicolumn{3}{|c|}{ Mean Rating } & \multirow{2}{*}{\begin{tabular}{|c|} 
Number \\
$1995-00$
\end{tabular}} \\
\hline & 1995-00 & $2001-5$ & 2006-12 & 1995-00 & $2001-5$ & 2006-12 & 1995-00 & $2001-5$ & 2006-12 & \\
\hline London: Big City & 29.7 & 26.6 & 22.5 & 39.0 & 42.8 & 42.8 & 2.9 & 2.6 & 2.6 & 135 \\
\hline London: Suburbs & 34.7 & 27.2 & 29.5 & 25.8 & 36.2 & 34.9 & 3.3 & 2.8 & 2.8 & 227 \\
\hline Non-London: Big City & 37.6 & 35.5 & 22.9 & 35.1 & 36.6 & 45.8 & 3.0 & 2.8 & 2.4 & 229 \\
\hline Non-London: Suburbs & 40.3 & 30.6 & 22.4 & 26.0 & 38.3 & 45.4 & 3.4 & 3.0 & 2.6 & 720 \\
\hline
\end{tabular}




\begin{tabular}{|c|c|c|c|c|c|c|c|c|c|c|}
\hline Non-London: Small City/Town & 37.7 & 29.0 & 21.0 & 27.5 & 35.5 & 42.9 & 3.3 & 2.9 & 2.6 & 1,934 \\
\hline Non-London: Country & 42.6 & 33.3 & 24.2 & 22.9 & 34.3 & 40.6 & 3.5 & 3.0 & 2.7 & 769 \\
\hline Great Britain & 38.7 & 30.2 & 22.7 & 27.0 & 36.2 & 42.5 & 3.3 & 2.9 & 2.6 & 4,014 \\
\hline
\end{tabular}

Source: British Social Attitudes Survey

Notes:

1. The type of area where the respondent resides started to be asked in the BSA survey in 1995.

2. The percentage of respondents in each category and mean ratings is weighted.

3. Respondents who did not provide an answer or did not know have been removed from the mean ratings.

4. The number of observations is based on all responses to the questions and is unweighted. 
Table 3: Characteristics of Respondents to Homosexual Relations Question in Urban-Rural Areas

\begin{tabular}{|c|c|c|c|c|c|c|c|c|c|c|c|c|}
\hline & \multicolumn{3}{|c|}{ Nonwhite } & \multicolumn{3}{|c|}{ Graduate } & \multicolumn{3}{|c|}{ Christian } & \multicolumn{3}{|c|}{ Other Religion } \\
\hline & 1995-00 & $2001-5$ & 2006-12 & 1995-00 & $\begin{array}{c}\text { 2001- } \\
5\end{array}$ & 2006-12 & 1995-00 & $\begin{array}{c}\text { 2001- } \\
5\end{array}$ & 2006-12 & $\begin{array}{c}\text { 1995- } \\
00\end{array}$ & $\begin{array}{c}\text { 2001- } \\
5\end{array}$ & $\begin{array}{c}\text { 2006- } \\
12\end{array}$ \\
\hline London: Big City (\%) & 25.2 & 32.8 & 37.8 & 25.9 & 29.1 & 35.0 & 61.2 & 45.5 & 40.6 & 10.4 & 15.7 & 18.2 \\
\hline London: Suburbs (\%) & 13.7 & 19.1 & 25.9 & 17.3 & 28.9 & 32.5 & 54.7 & 48.9 & 42.7 & 6.7 & 12.1 & 16.5 \\
\hline Non-London: Big City (\%) & 8.4 & 16.2 & 14.0 & 18.9 & 16.3 & 26.5 & 48.2 & 44.9 & 40.9 & 6.2 & 11.2 & 11.1 \\
\hline Non-London: Suburbs (\%) & 3.6 & 5.6 & 6.8 & 7.8 & 14.8 & 19.6 & 53.6 & 55.6 & 47.8 & 3.1 & 3.7 & 3.7 \\
\hline $\begin{array}{l}\text { Non-London: Small } \\
\text { City/Town }(\%)\end{array}$ & 3.0 & 4.6 & 4.9 & 9.3 & 13.6 & 17.2 & 52.9 & 53.7 & 48.7 & 1.6 & 2.6 & 3.4 \\
\hline Non-London: Country (\%) & 0.9 & 2.0 & 1.9 & 11.6 & 16.0 & 18.3 & 58.4 & 59.5 & 56.8 & 0.5 & 1.5 & 0.8 \\
\hline Great Britain (\%) & 4.4 & 6.9 & 7.2 & 11.1 & 15.9 & 19.8 & 54.2 & 54.0 & 49.4 & 2.5 & 4.2 & 4.4 \\
\hline Mean Attitudes (Category) & 3.5 & 3.6 & 3.6 & 2.3 & 2.2 & 2.1 & 3.6 & 3.2 & 3.0 & 3.8 & 3.6 & 3.7 \\
\hline Mean Attitudes (Rest) & 3.3 & 2.9 & 2.5 & 3.4 & 3.0 & 2.7 & 2.9 & 2.6 & 2.3 & 3.3 & 2.9 & 2.6 \\
\hline
\end{tabular}

Source: British Social Attitudes Survey 
Notes:

1. The percentage of respondents in each category is unweighted.

2. Mean attitudes to the homosexual relations question are weighted. Respondents who did not provide an answer or did not know have been removed from the mean ratings.

3. The comparatively high percentage of Christians in the Big City area of London in 1995-2000 is the result of a relatively large number of respondents identifying themselves as Christians in 1999 and 2000.

Table 4: Snapshot of Gay Partner Search Website and Apps 1800-1900 hrs (21/02/2015) 


\begin{tabular}{|c|c|c|c|c|}
\hline Location & $\begin{array}{l}\text { No. of Gaydar } \\
\text { Profiles }\end{array}$ & $\begin{array}{l}\text { No. Online } \\
\text { Gaydar }\end{array}$ & $\begin{array}{l}\text { No. Online } \\
\text { Growlr }\end{array}$ & $\begin{array}{l}\text { No. Online } \\
\text { Hornet }\end{array}$ \\
\hline \multicolumn{5}{|l|}{$\begin{array}{l}\text { North West } \\
\text { England }\end{array}$} \\
\hline Manchester & 597 & 145 & $>124$ & 355 \\
\hline Burnley & 246 & 40 & 52 & 16 \\
\hline Garstang & 6 & 2 & 8 & 1 \\
\hline \multicolumn{5}{|l|}{$\begin{array}{l}\text { North East } \\
\text { England }\end{array}$} \\
\hline Newcastle & 421 & 60 & $>124$ & 305 \\
\hline Durham & 391 & 72 & 20 & 65 \\
\hline Hexham & 18 & 4 & 4 & 6 \\
\hline \multicolumn{5}{|l|}{$\begin{array}{l}\text { Yorkshire and } \\
\text { Humberside }\end{array}$} \\
\hline Sheffield & 516 & 98 & $>124$ & 205 \\
\hline Scunthorpe & 165 & 37 & 24 & 14 \\
\hline Tadcaster & 6 & 1 & 3 & 1 \\
\hline \multicolumn{5}{|l|}{ East Midlands } \\
\hline Nottingham & 630 & 129 & 116 & 160 \\
\hline Grantham & 90 & 20 & 5 & 10 \\
\hline Melton Mowbray & 31 & 6 & 4 & 8 \\
\hline \multicolumn{5}{|l|}{ West Midlands } \\
\hline Birmingham & 347 & 118 & $>124$ & 485 \\
\hline Shrewsbury & 205 & 47 & 24 & 18 \\
\hline Polesworth & 0 & 0 & 2 & 0 \\
\hline \multicolumn{5}{|l|}{ East Anglia } \\
\hline Norwich & 566 & 132 & $>124$ & 127 \\
\hline Lowestoft & 147 & 30 & 12 & 34 \\
\hline
\end{tabular}




\begin{tabular}{|l|l|l|l|l|}
\hline Wells next the Sea & 0 & 0 & 3 & 3 \\
\hline & & & & \\
\hline South East & & & & \\
\hline Brighton & 188 & 186 & $>124$ & 305 \\
\hline Chichester & 204 & 44 & 11 & 35 \\
\hline Dymchurch & 6 & 2 & 1 & 3 \\
\hline & & & & \\
\hline $\begin{array}{l}\text { South West } \\
\text { England }\end{array}$ & & & & \\
\hline Plymouth & 462 & 81 & 100 & 130 \\
\hline Gloucester & 421 & 80 & 44 & 59 \\
\hline Mevagissey & 0 & 0 & 4 & 4 \\
\hline
\end{tabular}


Stage 4: 'Integration' - assimilation into the fashionable mainstream

Key features

1. Increasing custom of heterosexual custom in ostensibly gay pubs/bars

Conversion of some existing commercial premises for new mainstream society service-sector enterprises (bars, clubs, restaurants)

3. Influx of young urban professionals to the existing stock of residential units in the gay village environs

4. Equity gain realisation, outflow and suburbanisation of early gay residential colonisers

5. Housing cost pressures escalate for later gay residential in-movers.

6. High valuation of some gay-owned, partially owned or non-gay owned small businesses or franchises or chain-linked enterprises trigger some commercial sales.

7. Increasing applications and construction of new-build (apartment) residential units in the gay village environs.

8. Increasingly significant and sustained contribution to gay service-sector enterprises' revenue streams from the heterosexual community.

Stage 5: 'Fragmentation' - exploration and settlement of outer city areas

Key features:

1. Later gay residential in-movers explore and settle in cheaper, outer city twilight/edgier/marginal areas featuring some physical urban decay and proximity to one or more existing gay or bohemian, liberal mixed sexuality welcoming pub to form a nascent satellite gay district(s)

2. Lower property prices/rental values and presence of new gay customer base prompt new or franchises or chains of gay owned or gay-targeting businesses in satellite areas.

3. Increasing online partner search and more limited social/leisure commuting to traditional gay village environs by satellite area residents, reducing their revenue streams.

4. Further waves of business sales and thus gay village contraction and decline

5. Online partner search, liberal social attitudes and prohibitive housing costs stem the rate of in-flow of new gay in-movers to traditional gay village environs 
Stage 6: 'Deconcentration' - dissipation and dispersal of gay households and routine exploitation of mixed sexuality spaces

Key features:

1. Online partner search and social attitude change enabled routine and widespread use of mixed sexuality spaces erode the revenue streams of both traditional gay villages and satellite gay districts.

2. Online platforms for recreational, cultural and sporting social networks become increasingly visible and utilized.

3. Supported by 1 and 2 above prompts economic or child -focused or quality of life decisions by lesbian/gay individuals and households to move to, or remain in, suburban locations or small/medium sized towns or rural areas.

4. Disappearance of most non-core city-based urban gay villages and districts.

5. Contraction and rationalization of remaining core city urban gay villages, some featuring physical markers of commemoration for the LGBT path to liberation and equality. 
${ }^{\mathrm{i}}$ There has been a change in the regional variable used in the BSA from 2006, see notes to Table 1. Responses to the homosexual relations question have been grouped into periods because of the relatively small number of responses in some regions in any one year. The grouping of years into periods is not very sensitive to different options given the fairly constant change in attitudes towards homosexual relations.

ii The growth in the percentage of respondents stating that they had non-Christian religious beliefs was highest in both London areas and the mean attitudes of this group towards homosexual relations was fairly constant over the three periods, whereas it fell quite noticeably for Christians and non-religious people. These trends have been counter-balanced by London's continued ability to attract university graduates, although the share of graduates has risen in all of the areas and the tendency for more liberal attitudes towards homosexual relations has been more marked for non-graduates - narrowing the mean difference over the three periods from 1.1 to 0.6 .

iii It was not possible to add information for March 2010 since the listings of venues in Gay Times went online sometime before 2010. A list of current venues appears on the Gay Times website, and from viewing these details at the time of writing (July 2015), it would appear that there has been a decline in the number of listed venues in many towns and cities but that the decline in London may have been arrested to some extent, although direct comparisons are difficult. 